\title{
Effects of irisin on osteoblast apoptosis and osteoporosis in postmenopausal osteoporosis rats through upregulating Nrf2 and inhibiting NLRP3 inflammasome
}

\author{
LILI XU*, LIYAN SHEN* ${ }^{*}$ XIAOLONG YU, PENG LI, QING WANG and CHENGQIAN LI \\ Department of Endocrinology and Metabolism, The Affiliated Hospital of Qingdao University, \\ Qingdao, Shandong 266000, P.R. China
}

Received September 20, 2019; Accepted November 18, 2019

DOI: $10.3892 /$ etm.2019.8313

\begin{abstract}
The nuclear factor E2-related factor 2 (Nrf2)/NLR family, pyrin domain containing protein 3 (NLRP3) plays an important role in osteoporosis (OP), so the effects of irisin on postmenopausal OP rats and osteoblast apoptosis through Nrf2/NLRP3 were explored in the present study. A total of 45 specific pathogen-free Sprague-Dawley rats were selected and divided into OP model group (OP group, $\mathrm{n}=15), 1 \mathrm{mmol} / \mathrm{l}$ irisin treatment group (irisin group, $\mathrm{n}=15$ ) and normal control group (control group, $n=15$ ). After the trial period, the content of serum ALP was detected, the levels of tumor necrosis factor- $\alpha$ (TNF- $\alpha)$ in the serum and bone tissues were observed via ELISA, and the bone microstructure was observed via CT. Osteoblast apoptosis was determined through TUNEL assay, the content of apoptosis genes caspase-3 and Bcl-2, and key genes in Runt-related transcription factor 2 (Runx2), osteocalcin (OC), Nrf2 and NLRP3 was detected via RT-PCR. The protein expression of Bcl-2, Nrf2 and NLRP3 was determined via western blotting. The serum ALP level was increased in OP group compared with that in control group $(\mathrm{P}<0.05)$, while it declined in the irisin group. The content of TNF- $\alpha$ and interleukin-6 (IL-6) was significantly higher in OP group, while the content in the irisin group was close to that in the control group. The trabecular thickness, number and bone mineral density in the irisin group were all obviously larger and higher, respectively, than those in the OP group. The mRNA expression of Runx2, OC, Bcl-2 and Nrf2 in the irisin group were obviously higher $(\mathrm{P}<0.05)$, while that of caspase- 3 and NLRP3 showed the opposite trends. The protein expression of
\end{abstract}

Correspondence to: Dr Chengqian Li, Department of Endocrinology and Metabolism, The Affiliated Hospital of Qingdao University, 1677 Wutaishan Road, Huangdao, Qingdao, Shandong 266000, P.R. China

E-mail: cunq357@126.com

*Contributed equally

Key words: irisin, Nrf2, NLRP3 inflammasome, apoptosis, rats, postmenopausal osteoporosis
Bcl-2 and Nrf 2 in the irisin group was remarkably higher than those in the OP group, while that of NLRP3 was the opposite. irisin can upregulate Nrf2, inhibit NLRP3 inflammasome and lower the content of inflammatory factors, thereby suppressing osteoblast apoptosis in postmenopausal OP rats and reducing the incidence of postmenopausal OP.

\section{Introduction}

Postmenopausal osteoporosis (OP), a common debilitating disease characterized by low bone mineral density (BMD) and destruction of bone structure, seriously affects the health of the elderly, which is caused by osteopenia due to the decline in the female ovarian function with age. The pathophysiology of ovary-related bone loss is complicated and cannot be simply explained by the increase in bone resorption or decrease in bone formation, and there are various pathogeneses and regulatory factors $(1,2)$. Currently, it is urgent to search for satisfactory therapeutic methods for bone diseases such as OP (3). How to treat bone diseases more effectively is an urgent problem to be solved. The effects of multiple genes and other regulatory factors on OP are involved, and it is a complex and dynamic process regulated by a variety of cellular components and cytokines. Increasing osteoclast formation can accelerate cartilage reabsorption and promote bone union, while inhibiting osteoblast or osteoclast differentiation will suppress the healing of OP $(4,5)$. The damage to osteoclast absorption will release organic and inorganic compounds in the bone, the degraded compound substrates enter the blood circulation in the form of $\mathrm{Ca}^{2+}$, and the osteoclasts are responsible for cartilage absorption and remodeling through secreting acid and protease (6). After OP, cytokines will initiate osteogenic differentiation, which promotes the benign development of disease and maintains the benign dynamic balance $(7,8)$. Once the structural changes happen in bone tissues and the deposition of the bone matrix is destroyed, OP and fractures will occur (9). In recent years, great progress has been made in the treatment and prevention of female OP, and the treatment mainly focuses on increasing bone formation or decreasing bone resorption to reduce its incidence rate (10). Studies have demonstrated that the osteoblast and osteoclast formation is regulated by a variety of genes or proteins. The extracellular matrix proteins, such 
as Runt-related transcription factor 2 (Runx2), produced by osteoblasts can be positively controlled by the body and stably secreted, which is the basis to keep bone homeostasis (11). Therefore, deeply understanding these molecular regulatory networks is essential for the treatment of OP, and designing drugs targeting these genes or proteins will provide new ideas for the OP treatment and fracture healing.

Postmenopausal ovariectomy will facilitate bone loss, which is caused by estrogen deficiency (12). In recent years, studies have found that the growth, maturation, isolation and differentiation of osteoclasts in bone loss are synchronously regulated by multiple factors, and the signaling pathways directly involved in bone resorption play a key role (13). It has been found that nuclear factor E2-related factor 2 (Nrf2) and NLR family, pyrin domain containing protein 3 (NLRP3) play important roles in OP. According to recent studies, Nrf2 is an important regulator of bone balance in bone cells, and its activation can enhance the inhibition of endogenous antioxidant response on reactive oxygen species (ROS), thereby regulating the occurrence of OP $(14,15)$. Nrf2, through inducing antioxidant and phase II detoxification enzymes, plays an important role in the defense of cells against antioxidants and oxidative stress in the lifespan of the cells. Transcription factors regulate the expression of marrow stromal antioxidants and phase II enzymes (16). In addition, Nrf2 downregulates the NLRP3-mediated inflammatory process and innate immune response (17). The loss of Nrf2 leads to increased radiation, inducing OP (18). However, the effects of Nrf2 on bone metabolism and microstructure in vivo and its possible role in OP are not fully understood yet.

Irisin is a kind of novel actin and adipokine that is released into the blood circulation through the cleaved fibronectin type III domain (19). Irisin is mainly synthesized and secreted by skeletal muscles, so its correlation with muscles has been explored in several studies (20). Studies have demonstrated that irisin can serve as a biomarker for sarcopenia in postmenopausal women. In addition, although there are some studies on the correlation between irisin and OP and diabetes (21), no definite and consistent results have been obtained, and the specific molecular mechanism of treatment has not been fully clarified. Therefore, it is proposed in this study that irisin can have a positive influence on osteoblast apoptosis and OP in postmenopausal OP rats through upregulating Nrf2 and inhibiting NLRP3 inflammasome. The OP model was established, the biochemical indexes were detected, the content of inflammatory factors was determined via enzyme-linked immunosorbent assay (ELISA), and the bone microstructure was analyzed. Moreover, the changes in Nrf2, NLRP3 inflammasome, apoptosis and OP molecules were detected through gene and protein assays, so as to reveal the therapeutic effect of irisin on postmenopausal OP rats, and explore whether it exerts a regulatory effect on the recovery of osteoblast apoptosis and OP in postmenopausal OP rats through upregulating Nrf2 and inhibiting NLRP3 inflammasome, which provides an experimental basis for the subsequent research and development of new drugs.

\section{Materials and methods}

Animalmodeling and grouping. Healthy female Sprague-Dawley rats were selected and adaptively fed, and then the rat model of postmenopausal OP was established via ovariectomy. Fortyfive rats were divided into OP model group (OP group, $n=15$ ), $1 \mathrm{mmol} / \mathrm{l}$ irisin treatment group (irisin group, $\mathrm{n}=15$ ) and normal control group (control group, $n=15$ ). After the trial period, the blood was drawn from the caudal vein and centrifuged, and the serum was collected and stored at $-80^{\circ} \mathrm{C}$ to detect the serum biochemical indexes. Then the rats were anesthetized with pentobarbital sodium, and an appropriate number of bone tissues were taken, one part for ELISA and the other part was stored at $-80^{\circ} \mathrm{C}$ to detect expression of genes and proteins. Interleukin-6 (IL-6) and tumor necrosis factor- $\alpha$ (TNF- $\alpha$ ) kits were purchased from Sangon and antibodies from Abcam.

The study was approved by the Ethics Committee of the Affiliated Hospital of Qingdao University (Qingdao, China).

Detection of serum biochemical indexes. The serum stored at $-80^{\circ} \mathrm{C}$ was taken out, slowly thawed at $-20^{\circ} \mathrm{C}$ and centrifuged at $120 \mathrm{x} \mathrm{g}$ for $10 \mathrm{~min}$ at $4^{\circ} \mathrm{C}$. The supernatant was collected and subpackaged into $1.5 \mathrm{ml} \mathrm{EP}$ tubes to detect the content of serum alkaline phosphatase (ALP) using a full-automatic biochemical analyzer. The raw data were recorded and then analyzed.

Detection of serum osteocalcin (OC), TNF- $\alpha$ and IL-6 in serum and bone tissues by ELISA. An appropriate number of bone tissues stored at $-80^{\circ} \mathrm{C}$ were ground using a mortar, added with lysis buffer (strong) and centrifuged at 2,000 x $\mathrm{g}$ for $10 \mathrm{~min}$ at $4^{\circ} \mathrm{C}$. Then the supernatant was collected to detect the changes in TNF- $\alpha$, OC and IL- 6 levels in tissues according to the instructions. The absorbance of indexes in each group was detected using a microplate reader, and the standard curves were plotted to analyze the changes.

Micro-CT observation of bone microstructure. The vertebral bone was isolated in vitro and placed in a Micro-CT sample cup (GE Healthcare) for three-dimensional CT reconstruction. The trabecular thickness (Tb.Th), trabecular number (Tb.N), trabecular separation (Tb.Sp) and Micro-CT BMD were analyzed.

TUNEL apoptosis assay. Apoptosis of paraffin sections was detected using the in situ cell death detection kit (Roche Diagnostics). Paraffin sections were fixed, rinsed and infiltrated with $0.1 \%$ Triton X-100, followed by FITC end labeling of apoptotic DNA fragment using the TUNEL assay kit (Beyotime Institute of Biotechnology). The FITC-labeled TUNEL-positive cells were observed under a fluorescence microscope, and they were counted in 10 fields of view.

Detection of important molecules and pathway-related genes in bone tissues by RT-PCR. An appropriate number of bone tissues stored at $-80^{\circ} \mathrm{C}$ were added with liquid nitrogen and ground using a mortar, followed by homogenization under $4^{\circ} \mathrm{C}$ at $800 \mathrm{x} \mathrm{g}$ for several seconds. The total RNA was extracted from tissues, and the RNA purity and concentration were determined qualified. The primer sequences of target genes and the internal reference GAPDH were designed according to GenBank (Table I). RNA was reverse transcribed into cDNA using a kit (Invitrogen; Thermo Fisher Scientific, Inc.) and the PCR amplification was performed using $20 \mu \mathrm{l}$ of system $(2 \mu \mathrm{l}$ 
Table I. Primer sequences of target genes.

\begin{tabular}{ll}
\hline Target gene & \multicolumn{1}{c}{ Primer sequence (5'-3') } \\
\hline$\beta$-actin & ACATGCCGCCTGGAGAAA \\
& GCCCAGGATGCCCTTTAG \\
Bcl-2 & GTGCTCTTGAGATCTCTGG \\
& CATCGATCTTCAGAAGTCTC \\
Caspase-3 & TACCGCACCCGGTTACTAT \\
& TCCGGTTAACACGAGTGAG \\
Runx2 & TCCAACCCGTAAGGTGACG \\
& GCTGCTGAGTCGATGCTAGC \\
OC & TCGTAGCTAGCTAGTCGAGC \\
& CCCTGTGCTAGCTAGCTAGC \\
Nrf2 & GGCTGGGCCAAGATCCTA \\
& ATAGTCCGCAGGTACCTC \\
NLRP3 & TGTTCACTGTTCCTAATC \\
& CTGAAACACTGGCTTAAA
\end{tabular}

Runx2, Runt-related transcription factor 2; OC, osteocalcin; Nrf2, nuclear factor E2-related factor 2; NLRP3, NLR family, pyrin domain containing protein 3 .

of cDNA, $10 \mu \mathrm{l}$ of qPCR mix, $1 \mu \mathrm{l}$ of primer $\mathrm{F}, 1 \mu \mathrm{l}$ of primer $\mathrm{R}$ and $6 \mu \mathrm{l}$ of $\mathrm{ddH}_{2} \mathrm{O}$ ): at $95^{\circ} \mathrm{C}$ for $2 \mathrm{~min}, 94^{\circ} \mathrm{C}$ for $20 \mathrm{sec}, 60^{\circ} \mathrm{C}$ for $20 \mathrm{sec}$ and $72^{\circ} \mathrm{C}$ for $30 \mathrm{sec}$, a total of 40 cycles. The specific primer sequences are shown in Table I. The relative expression levels of related genes in tissues in each group were calculated using $2^{-\Delta \Delta \mathrm{Ct}}$.

Western blotting. The tissues stored in the ultra low temperature refrigerator were added with lysis buffer (strong) prepared proportionally, incubated at $-20^{\circ} \mathrm{C}$ for $20 \mathrm{~min}$ and ground, followed by centrifugation at $2,000 \mathrm{x}$ for $10 \mathrm{~min}$ at $4^{\circ} \mathrm{C}$. The supernatant was collected and the protein concentration was measured using the standard curves. After that, western blotting was performed. Protein $(50 \mu \mathrm{g})$ was added with buffer to prepare the protein samples, subjected to water bath for $8 \mathrm{~min}$ and centrifuged at $1,000 \mathrm{xg}$ for $5 \mathrm{~min}$ at $4^{\circ} \mathrm{C}$. Then the protein was loaded for electrophoresis, transferred onto a membrane, sealed, incubated with the primary antibody overnight and incubated again with the secondary antibody for $1 \mathrm{~h}$. Finally, the protein band was scanned and quantified using the protein scanner (Bio-Rad Laboratories) and the level of protein to be detected was corrected using GAPDH.

Statistical analysis. All raw data obtained in the experiments were statistically analyzed using SPSS 20.0 software. The experimental results were expressed as mean \pm standard deviation (mean $\pm \mathrm{SD}$ ). $\mathrm{P}<0.05$ indicates that the difference was statistically significant. The bar graph was plotted using GraphPad Prism 7.0.

\section{Results}

Results of serum biochemical indexes. OP can be predicted through early biochemical indexes to prepare for the treatment

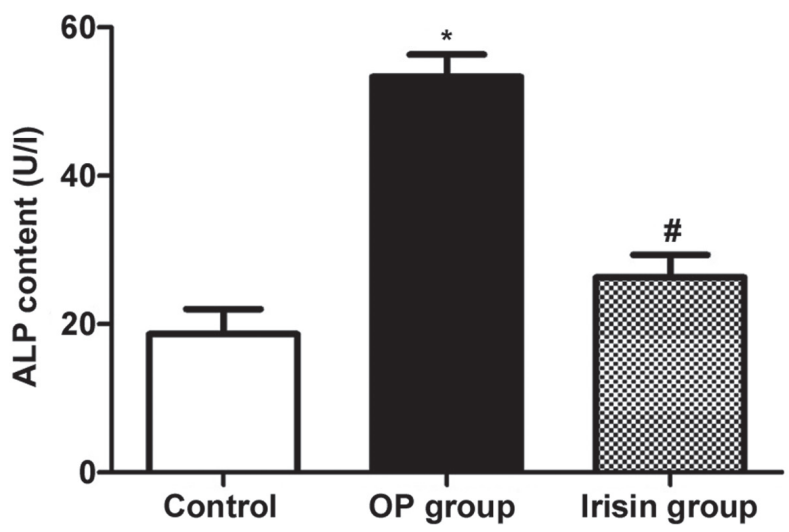

Figure 1. Serum ALP content. The content of ALP is significantly increased in OP group $(\mathrm{P}<0.05)$, and declines in irisin group. ${ }^{*} \mathrm{P}<0.05$ vs. control group; ${ }^{\#} \mathrm{P}<0.05$ vs. OP group.

and prognosis as early as possible, so the content of serum ALP was measured and recorded for analysis. As shown in Fig. 1, the content of ALP was significantly increased in OP group $(\mathrm{P}<0.05)$, and declined in irisin group.

Levels of OC, TNF- $\alpha$ and IL- 6 detected by ELISA. As shown in Table II, the content of serum OC was significantly decreased in the OP group $(\mathrm{P}<0.05)$, and increased in the irisin group $(\mathrm{P}<0.05)$. The content of IL- 6 and TNF- $\alpha$ was increased in the OP group $(\mathrm{P}<0.05)$, and decreased in the irisin group $(\mathrm{P}<0.05)$.

TNF- $\alpha$ and IL- 6 levels in bone tissues detected by ELISA. As shown in Table III, the content of IL- 6 and TNF- $\alpha$ was increased in the OP group $(\mathrm{P}<0.05)$, and declined in the irisin group $(\mathrm{P}<0.05)$.

Micro- $C T$ results. To observe the therapeutic effect of irisin on OP from the microstructure, Tb.Th, Tb.N, Tb.Sp and BMD were detected. The results revealed that in the irisin group, Tb.Th, Tb.N and BMD were obviously increased compared with those in the OP group $(\mathrm{P}<0.05)$, while Tb.Sp obviously declined compared with that in the OP group $(\mathrm{P}<0.05)$ (Table IV).

TUNEL apoptosis assay. There were few TUNEL-positive cells and they could hardly be observed in the control group. The number of TUNEL-positive cells was remarkably more in the OP group than that in the other two groups, while it was less in the irisin group $(\mathrm{P}<0.05)$ (Fig. 2), indicating that irisin can inhibit osteoblast apoptosis in OP.

RT-PCR results of apoptosis and OP-related genes. Compared with the OP group, the irisin group had evidently higher mRNA expression levels of Runx2, OC, Bcl-2 and Nrf2 $(\mathrm{P}<0.05)$, while caspase-3 and NLRP3 displayed the opposite trends (Fig. 3), suggesting that irisin can inhibit the incidence of apoptosis in OP and the occurrence and development of OP.

Western blotting. The protein expression levels of Bcl-2 and Nrf2 in the irisin group were remarkably higher than those in the OP group, while that of NLRP3 was the opposite (Fig. 4), 


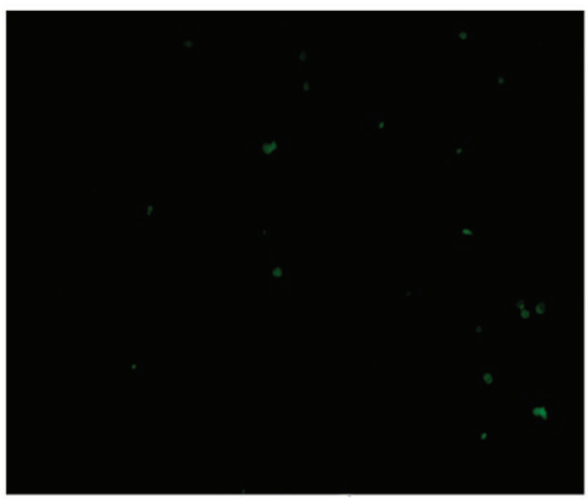

Control

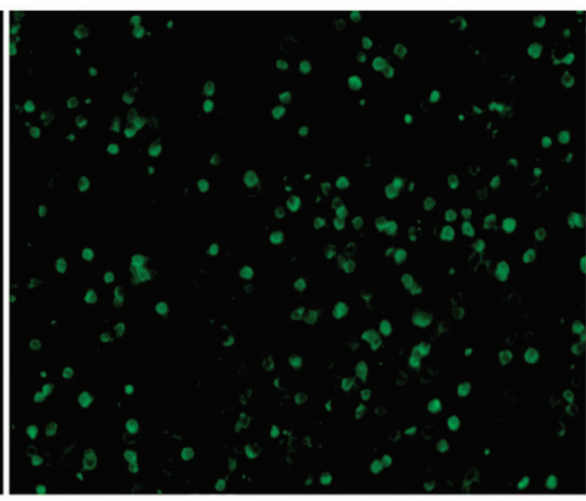

OP group

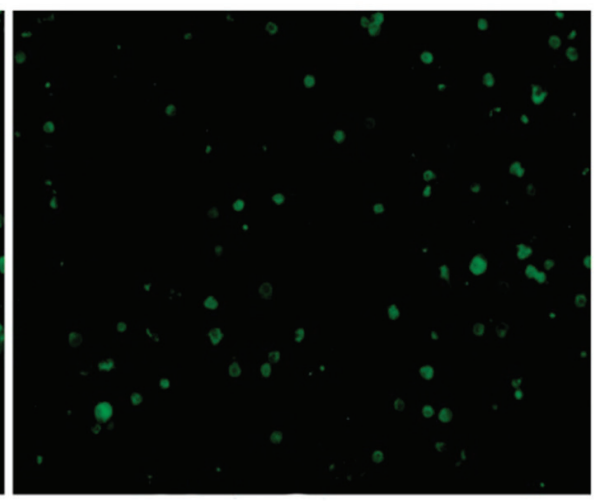

Irisin group

Figure 2. TUNEL staining. There are few TUNEL-positive cells and they can hardly be observed in the control group. The number of TUNEL-positive cells is remarkably more in the OP group than that in the other two groups, while it is less in the irisin group $(\mathrm{P}<0.05)$.

Table II. ELISA results of serum indexes.

\begin{tabular}{lccc}
\hline Group & $\begin{array}{c}\text { OC } \\
(\mathrm{ng} / \mathrm{ml})\end{array}$ & $\begin{array}{c}\text { IL-6 } \\
(\mathrm{mg} / \mathrm{l})\end{array}$ & $\begin{array}{c}\text { TNF- } \alpha \\
(\mathrm{fmol} / \mathrm{ml})\end{array}$ \\
\hline Control & $11.26 \pm 0.56$ & $30.35 \pm 5.24$ & $18.63 \pm 3.28$ \\
OP & $4.9 \pm 0.45^{\mathrm{a}}$ & $99.64 \pm 7.37^{\mathrm{a}}$ & $39.58 \pm 5.78^{\mathrm{a}}$ \\
Irisin & $8.99 \pm 0.78^{\mathrm{b}}$ & $35.66 \pm 3.86^{\mathrm{b}}$ & $22.47 \pm 5.85^{\mathrm{b}}$ \\
\hline
\end{tabular}

The content of IL- 6 and TNF- $\alpha$ is increased in OP group $(\mathrm{P}<0.05)$, and decreased in the irisin group $(\mathrm{P}<0.05)$, while the content of OC shows the opposite trends. ${ }^{\mathrm{P}}<0.05$ vs. control group; ${ }^{\mathrm{b}} \mathrm{P}<0.05 \mathrm{vs}$. OP group. ELISA, enzyme-linked immunosorbent assay; OC, osteocalcin; OP, osteoporosis; TNF- $\alpha$, tumor necrosis factor- $\alpha$; IL-6, interleukin-6.

demonstrating that irisin not only inhibits the incidence of apoptosis, but can also treat OP through upregulating Nrf2 and inhibiting NLRP3 expression.

\section{Discussion}

In women, hormonal changes caused by menopause can lead to muscle atrophy, accelerate bone loss and enhance oxidative stress. During menopause, therefore, physiological degradation related to aging and underactivity may be increased, promoting the occurrence and development of OP $(22,23)$. Currently, the treatment mainly focuses on increasing bone formation or decreasing bone resorption to reduce its incidence rate (24). Physical activity plays an important role in resisting the physiological degradation related to aging and menopause, which is a potential mechanism, possibly because, on the one hand, physical exercise can produce mechanical signals directly through muscle strength or exert an anabolic effect on the bones indirectly through endocrine regulation, but its specific molecular mechanism remains unclear (25), and, on the other hand, chronic exercise training can reduce inflammatory and oxidative damage through enhancing antioxidant capacity and weakening oxidative stress. In many studies, some plants are used as traditional medicines with an anti-aging property. Recently, the potential beneficial effects of these plants on physiological functions, including the antioxidant capacity,
Table III. Results of inflammatory factors.

\begin{tabular}{llc}
\hline Group & IL-6 (mg/l) & TNF- $\alpha(\mathrm{fmol} / \mathrm{ml})$ \\
\hline Control & $19.34 \pm 5.41$ & $14.26 \pm 4.10$ \\
OP & $60.38 \pm 6.52^{\mathrm{a}}$ & $29.36 \pm 6.52^{\mathrm{a}}$ \\
Irisin & $22.24 \pm 3.65^{\mathrm{b}}$ & $19.99 \pm 5.58^{\mathrm{b}}$ \\
\hline
\end{tabular}

The content of IL- 6 and TNF- $\alpha$ is increased in the OP group $(\mathrm{P}<0.05)$, and declined in the irisin group $(\mathrm{P}<0.05)$. ${ }^{\mathrm{a}} \mathrm{P}<0.05$ vs. control group; ${ }^{b} \mathrm{P}<0.05$ vs. OP group. TNF- $\alpha$, tumor necrosis factor- $\alpha$; IL- 6 , interleukin-6; OP, osteoporosis.

have been studied increasingly (26). Among them, irisin is able to resist OP. OP can be predicted through early biochemical indexes to prepare for the treatment and prognosis as early as possible, so the classic rat model of postmenopausal OP was established, and the content of serum ALP was measured in the present study. The results showed that the content of ALP was significantly increased in the OP group and declined in the irisin group. The content of IL- 6 and TNF- $\alpha$ was also increased in the OP group and decreased in the irisin group. Serum OC can indicate the therapeutic effect of irisin on OP. It was found that the content of serum OC was significantly decreased in the OP group and increased in the irisin group, suggesting that irisin has a good therapeutic effect on OP. In addition, it was observed in bone microstructure during treatment that both $\mathrm{Tb} . \mathrm{N}$ and $\mathrm{Tb} . \mathrm{Th}$ in the irisin group were obviously increased compared with those in the OP group. The above results demonstrate that irisin can treat OP through affecting serum ALP, OC and inflammatory factors, consistent with the results of Yamaza et al (27) and Yang et al (28).

Studies have manifested that apoptosis can promptly remove the garbage produced by cells in the life-sustaining activity, supply energy for the formation of cellular structure and metabolism, and maintain cell stability (29). The mechanism and pathway clarified can be used as important guides for diseases such as OP. In the present study, the apoptosis level in each group was detected by TUNEL staining. There were few TUNEL-positive cells and they could hardly be observed in the control group. The number of TUNEL-positive cells 
Table IV. Micro-CT observation and analysis results of bone microstructure.

\begin{tabular}{|c|c|c|c|c|}
\hline Group & Tb.Th (mm) & Tb.N $\left(\mathrm{mm}^{-1}\right)$ & Tb.Sp (mm) & $\operatorname{BMD}\left(\mathrm{mg} / \mathrm{cm}^{3}\right)$ \\
\hline Control & $0.18 \pm 0.01$ & $4.8 \pm 0.03$ & $0.13 \pm 0.01$ & $415.2 \pm 11.8$ \\
\hline $\mathrm{OP}$ & $0.07 \pm 0.01^{\mathrm{a}}$ & $1.5 \pm 0.04^{\mathrm{a}}$ & $0.70 \pm 0.02^{\mathrm{a}}$ & $148.6 \pm 11.8^{\mathrm{a}}$ \\
\hline Irisin & $0.13 \pm 0.02^{\mathrm{b}}$ & $4.2 \pm 0.02^{\mathrm{b}}$ & $0.26 \pm 0.01^{\mathrm{b}}$ & $385.9 \pm 10.2^{b}$ \\
\hline
\end{tabular}

In the observation of bone microstructure, Tb.Th, Tb.N and BMD in he irisin group are obviously increased compared with those in the OP group $(\mathrm{P}<0.05)$, while Tb.Sp obviously declined compared with that in $\mathrm{OP}$ group $(\mathrm{P}<0.05)$. ${ }^{\mathrm{a}} \mathrm{P}<0.05$ vs. control group; ${ }^{\text {b }} \mathrm{P}<0.05$ vs. $\mathrm{OP}$ group. Tb.Th, trabecular thickness; Tb.N, trabecular number; Tb.Sp, trabecular separation; BMD, bone mineral density; OP, osteoporosis.

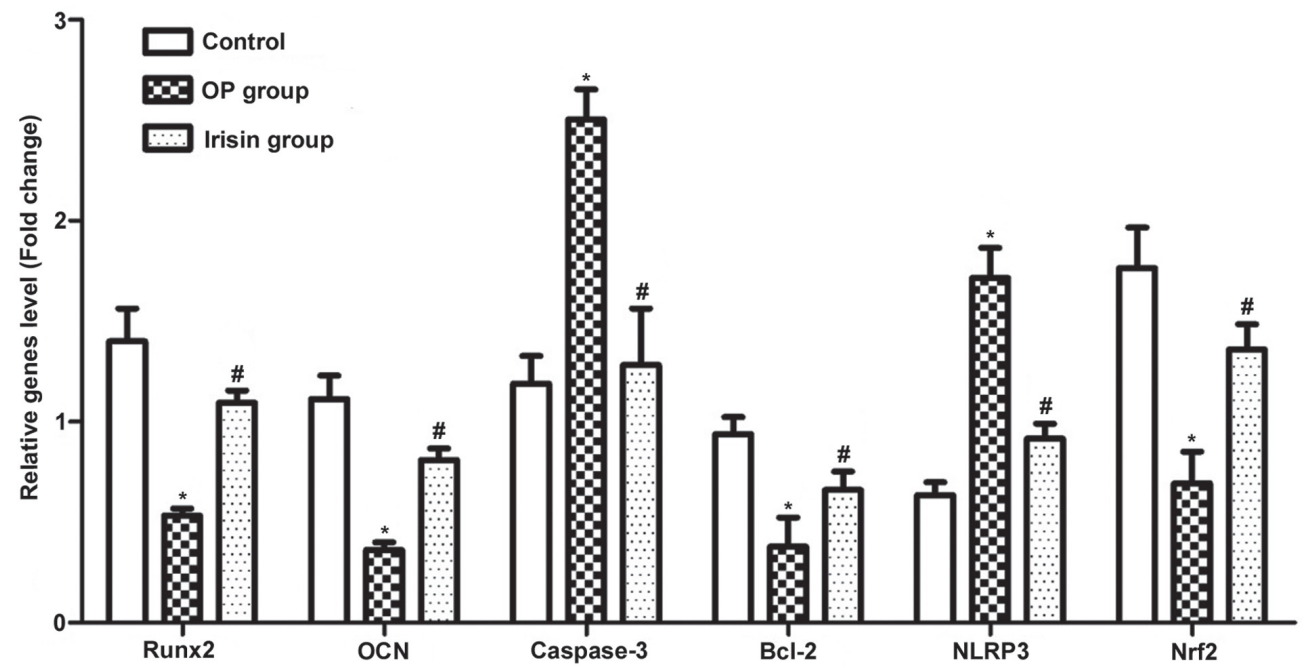

Figure 3. RT-PCR results. Compared with the OP group, the irisin group has evidently higher mRNA expression levels of Runx2, OC, Bcl-2 and Nrf2 (P<0.05), while caspase- 3 and NLRP 3 display the opposite trends. ${ }^{*} \mathrm{P}<0.05$ vs. control group; ${ }^{*} \mathrm{P}<0.05$ vs. OP group.

A
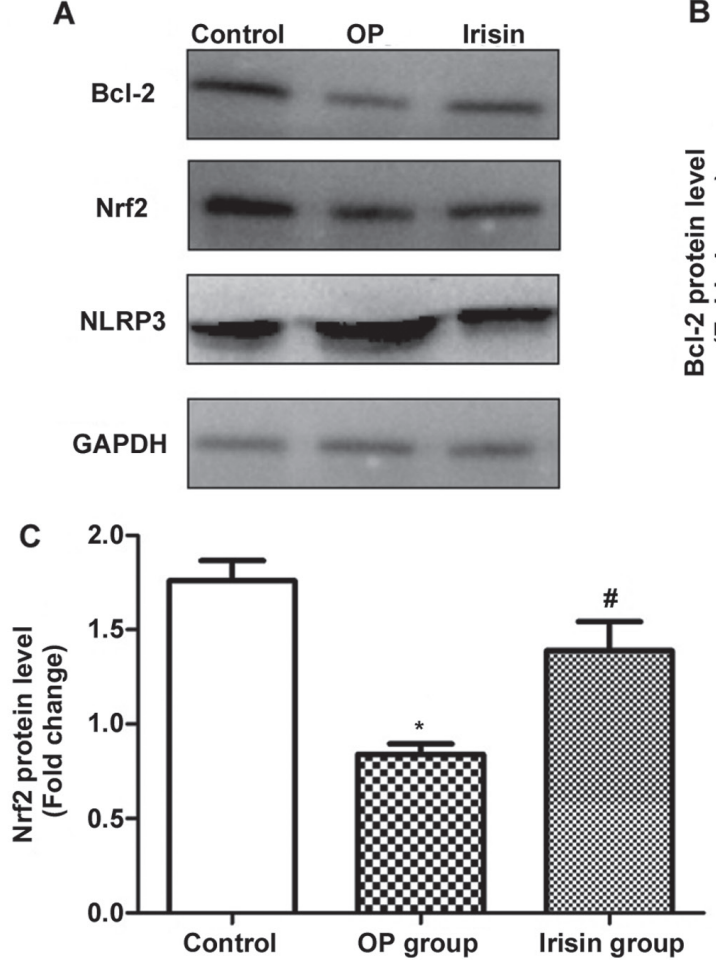

B
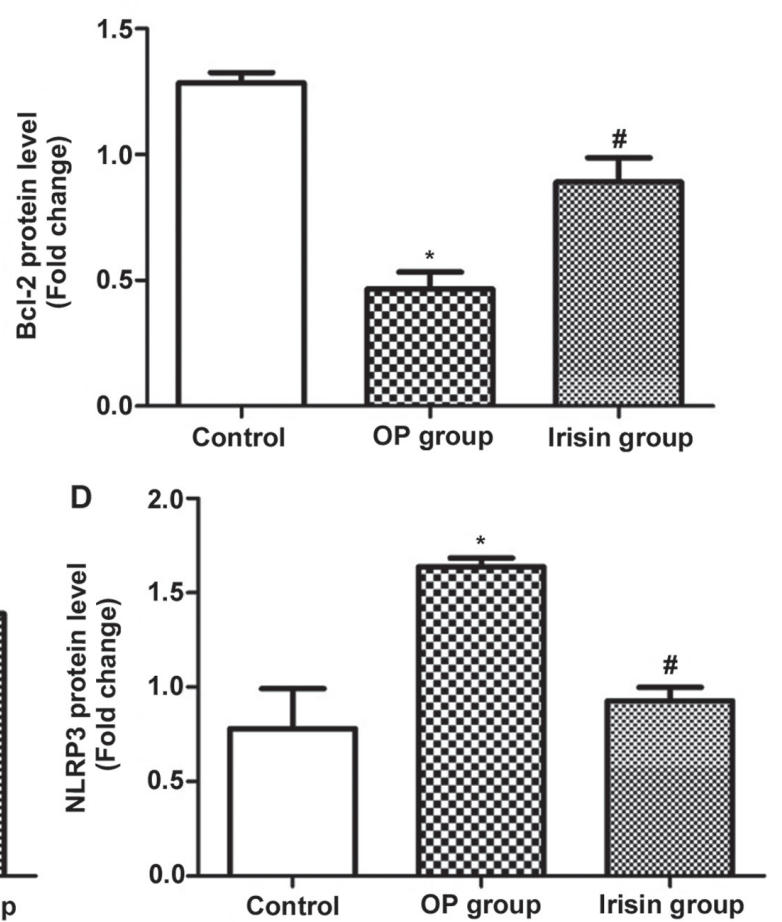

Figure 4. Protein detection results. (A) Western blot bands of Bcl-2, Nrf2 and NLRP3 protein expression in the three groups; (B and C) the protein expression levels of Bcl-2 and Nrf2 in the irisin group are remarkably higher than those in OP group; (D) the protein expression level of NLRP3 is the opposite. ${ }^{*} \mathrm{P}<0.05$ vs. control group; ${ }^{\#} \mathrm{P}<0.05$ vs. OP group. 
was remarkably more in the OP group than that in the other two groups, while it was less in the irisin group, indicating that irisin can inhibit apoptosis. In OP, bone morphogenetic protein 2-induced osteogenic differentiation is significantly damaged (30). Moreover, bone formation plays a unique and important role in the body after birth, which ultimately increases the expression of bone matrix proteins mainly through activating some important bone-derived transcription factors, such as Runx2. A kind of connexin, $\mathrm{OC} 1$ is found in pre-osteoblasts, which can connect Smad protein and actin microfilament. The knockout of $\mathrm{OCl}$ can clearly increase the incidence of OP (31). The Nrf2 signaling pathway is a key regulatory factor for bone metabolism (32). Studies have found that there are more osteoclasts in the bone marrow precursors cultured in $\mathrm{KO}$, and the deficiency of $\mathrm{Nrf} 2$ can also increase the survival rate of osteoclasts. According to the analysis of bone parameters of Nrf2 knockout mice and wild-type mice, Nrf2 is essential for keeping the bone quality (33). Moreover, both BMD and area of cortical bone decline in Nrf2 knockout mice. Nrf2-induced TESE changes may lead to OP and fractures. Studies have also manifested that the ROS production is increased in bone marrow cells in Nrf2 knockout mice receiving sham operation or ovariectomy, confirming that Nrf2 knockout can increase the number of osteoclasts in vivo (34). In this study, the RT-PCR results revealed that the irisin group had evidently higher mRNA expression levels of Runx2, OC, Bcl-2 and Nrf2 than the other two groups, while caspase-3 and NLRP3 displayed the opposite trends, which suggests that irisin can inhibit the incidence of apoptosis in OP and the occurrence and development of OP. Also, the protein expression levels of $\mathrm{Bcl}-2$ and $\mathrm{Nrf} 2$ in the irisin group were remarkably higher than those in the OP group, while that of NLRP3 was the opposite, demonstrating that irisin can not only inhibit the incidence of apoptosis, but also treat OP through upregulating Nrf2 and inhibiting NLRP3 expression. Such an effect was confirmed in the research results. However, the therapeutic effect of irisin needs further verification in in vivo experiments.

In conclusion, it was found that after the treatment of OP with irisin, the related inflammatory factors improved. The mRNA levels of OP healing-related markers such as Runx2 are significantly upregulated, osteoblast apoptosis declines, the Nrf2 expression is enhanced and the NLRP3 expression is suppressed. Therefore, the research results herein confirm that irisin inhibits the incidence of apoptosis, but also treats postmenopausal OP through upregulating Nrf2 and inhibiting NLRP3 expression.

\section{Acknowledgements}

Not applicable.

\section{Funding}

No funding was received.

\section{Availability of data and materials}

The datasets used and/or analyzed during the current study are available from the corresponding author on reasonable request.

\section{Authors' contributions}

LX and LS wrote the manuscript. XY and PL were responsible for establishment of the animal model. LX and LS performed TUNEL and Western blotting. QW and CL performed ELISA and other experiments. All authors read and approved the final manuscript.

\section{Ethics approval and consent to participate}

The study was approved by the Ethics Committee of the Affiliated Hospital of Qingdao University (Qingdao, China).

\section{Patient consent for publication}

Not applicable.

\section{Competing interests}

The authors declare that they have no competing interests.

\section{References}

1. Zhang J, Lazarenko OP, Blackburn ML, Shankar K, Badger TM, Ronis MJ and Chen JR: Feeding blueberry diets in early life prevent senescence of osteoblasts and bone loss in ovariectomized adult female rats. PLoS One 6: e24486, 2011.

2. Zhao X, Wu ZX, Zhang Y, Gao MX, Yan YB, Cao PC, Zang Y and Lei W: Locally administered perindopril improves healing in an ovariectomized rat tibial osteotomy model. PLoS One 7: e33228, 2012.

3. Cano A, Chedraui P, Goulis DG, Lopes P, Mishra G, Mueck A, Senturk LM, Simoncini T, Stevenson JC, Stute P, et al: Calcium in the prevention of postmenopausal osteoporosis: EMAS clinical guide. Maturitas 107: 7-12, 2018.

4. Kikuta J and Ishii M: Bone imaging: Osteoclast and osteoblast dynamics. Methods Mol Biol 1763: 1-9, 2018

5. Yu-Lee LY, Yu G, Lee YC, Lin SC, Pan J, Pan T, Yu KJ, Liu B, Creighton CJ, Rodriguez-Canales J, et al: Osteoblast-secreted factors mediate dormancy of metastatic prostate cancer in the bone via activation of the TGF $\beta$ RIII-p38MAPK-pS249/T252RB pathway. Cancer Res 78: 2911-2924, 2018.

6. Matsuo K: Cross-talk among bone cells. Curr Opin Nephrol Hypertens 18: 292-297, 2009.

7. Lee WC, Guntur AR, Long F and Rosen CJ: Energy metabolism of the osteoblast: Implications for osteoporosis. Endocr Rev 38: 255-266, 2017.

8. Black DM and Rosen CJ: Clinical practice. Postmenopausal osteoporosis. N Engl J Med 374: 254-262, 2016.

9. Cheung WH, Miclau T, Chow SK, Yang FF and Alt V: Fracture healing in osteoporotic bone. Injury 47 (Suppl 2): S21-S26, 2016.

10. Sanchez C, Mazzucchelli G, Lambert C, Comblain F, DePauw E and Henrotin Y: Comparison of secretome from osteoblasts derived from sclerotic versus non-sclerotic subchondral bone in OA: A pilot study. PLoS One 13: e0194591, 2018.

11. Hara Y, Ghazizadeh M, Shimizu H, Matsumoto H, Saito N, Yagi T, Mashiko K, Mashiko K, Kawai M and Yokota H: Delayed expression of circulating TGF- $\beta 1$ and BMP-2 levels in human nonunion long bone fracture healing. J Nippon Med Sch 84: 12-18, 2017.

12. Folwarczna J, Zych M and Trzeciak HI: Effects of curcumin on the skeletal system in rats. Pharmacol Rep 62: 900-909, 2010

13. Uemura H, Yasui T, Miyatani Y, Yamada M, Hiyoshi M, Arisawa $\mathrm{K}$ and Irahara M: Circulating profiles of osteoprotegerin and soluble receptor activator of nuclear factor kappaB ligand in post-menopausal women. J Endocrinol Invest 31: 163-168, 2008.

14. Ibáñez L, Ferrándiz ML, Brines R, Guede D, Cuadrado A and Alcaraz MJ: Effects of Nrf2 deficiency on bone microarchitecture in an experimental model of osteoporosis. Oxid Med Cell Longev 2014: 726590, 2014.

15. Park CK, Lee Y, Kim KH, Lee ZH, Joo M and Kim HH: Nrf2 is a novel regulator of bone acquisition. Bone 63: 36-46, 2014. 
16. Zhu H, Zhang L, Itoh K, Yamamoto M, Ross D, Trush MA Zweier JL and Li Y: Nrf2 controls bone marrow stromal cell susceptibility to oxidative and electrophilic stress. Free Radic Biol Med 41: 132-143, 2006.

17. Maicas N, Ferrándiz ML, Brines R, Ibáñez L, Cuadrado A, Koenders MI, van den Berg WB and Alcaraz MJ: Deficiency of Nrf2 accelerates the effector phase of arthritis and aggravates joint disease. Antioxid Redox Signal 15: 889-901, 2011.

18. Aw Yeang HX, Hamdam JM, Al-Huseini LM, Sethu S, Djouhri L, Walsh J, Kitteringham N, Park BK, Goldring CE and Sathish JG: Loss of transcription factor nuclear factor-erythroid 2 (NF-E2) p45-related factor-2 (Nrf2) leads to dysregulation of immune functions, redox homeostasis, and intracellular signaling in dendritic cells. J Biol Chem 287: 10556-10564, 2012.

19. Lee P, Linderman JD, Smith S, Brychta RJ, Wang J, Idelson C, Perron RM, Werner CD, Phan GQ, Kammula US, et al: Irisin and FGF21 are cold-induced endocrine activators of brown fat function in humans. Cell Metab 19: 302-309, 2014.

20. Lee MJ, Lee SA, Nam BY, Park S, Lee SH, Ryu HJ, Kwon YE, Kim YL, Park KS, Oh HJ, et al: Irisin, a novel myokine is an independent predictor for sarcopenia and carotid atherosclerosis in dialysis patients. Atherosclerosis 242: 476-482, 2015.

21. Palermo A, Strollo R, Maddaloni E, Tuccinardi D, D'Onofrio L, Briganti SI, Defeudis G, De Pascalis M, Lazzaro MC, Colleluori G, et al: Irisin is associated with osteoporotic fractures independently of bone mineral density, body composition or daily physical activity. Clin Endocrinol (Oxf) 82: 615-619, 2015.

22. Velders M and Diel P: How sex hormones promote skeletal muscle regeneration. Sports Med 43: 1089-1100, 2013.

23. Bednarek-Tupikowska G, Tupikowski K, Bidzińska B Bohdanowicz-Pawlak A, Antonowicz-Juchniewicz J, Kosowska B and Milewicz A: Serum lipid peroxides and total antioxidant status in postmenopausal women on hormone replacement therapy. Gynecol Endocrinol 19: 57-63, 2004.

24. Tu KN, Lie JD, Wan CKV, Cameron M, Austel AG, Nguyen JK, Van K and Hyun D: Osteoporosis: A review of treatment options. PT 43: 92-104, 2018.

25. Zhang L, Yin X, Wang J, Xu D, Wang Y, Yang J, Tao Y, Zhang S, Feng $\mathrm{X}$ and Yan C: Associations between VDR gene polymorphisms and osteoporosis risk and bone mineral density in postmenopausal women: A systematic review and meta-analysis. Sci Rep 8: 981-989, 2018.
26. Saei-Dehkordi SS, Tajik H, Moradi M and Khalighi-Sigaroodi F: Chemical composition of essential oils in Zataria multiflora Boiss. from different parts of Iran and their radical scavenging and antimicrobial activity. Food Chem Toxicol 48: 1562-1567, 2010.

27. Yamaza T, Miura Y, Bi Y, Liu Y, Akiyama K, Sonoyama W, Patel V, Gutkind S, Young M, Gronthos S, et al: Pharmacologic stem cell based intervention as a new approach to osteoporosis treatment in rodents. PLoS One 3: e2615, 2008.

28. Yang C, Zeng YP and Yang T: Irisin in restraining IL-1, IL-6, TNF- $\alpha$ and M-CSF expression and its effect in preventing post-menopause osteoporosis. China Pharmaceuticals 24: 15-17, 2015.

29. Klionsky DJ: Autophagy: From phenomenology to molecular understanding in less than a decade. Nat Rev Mol Cell Biol 8: 931-937, 2007.

30. Thirunavukkarasu K, Halladay DL, Miles RR, Yang X, Galvin RJ, Chandrasekhar S, Martin TJ and Onyia JE: The osteoblast-specific transcription factor Cbfal contributes to the expression of osteoprotegerin, a potent inhibitor of osteoclast differentiation and function. J Biol Chem 275: 25163-25172, 2000.

31. Xu H, Wu F, Zhang H, Yang C, Li K, Wang H, Yang H, Liu Y, Ding B, Tan Y, et al: Actin cytoskeleton mediates BMP2-Smad signaling via calponin 1 in preosteoblast under simulated microgravity. Biochimie 138: 184-193, 2017.

32. Kanzaki H, Shinohara F, Kajiya M and Kodama T: The Keap1/Nrf2 protein axis plays a role in osteoclast differentiation by regulating intracellular reactive oxygen species signaling. J Biol Chem 288: 23009-23020, 2013.

33. Pellegrini GG, Morales CC, Wallace TC, Plotkin LI and Bellido T: Avenanthramides prevent osteoblast and osteocyte apoptosis and induce osteoclast apoptosis in vitro in an Nrf2-independent manner. Nutrients 8: 423-436, 2016.

34. Ibáñez L, Ferrándiz ML, Brines R, Guede D, Cuadrado A and Alcaraz MJ: Effects of Nrf2 deficiency on bone microarchitecture in an experimental model of osteoporosis. Oxid Med Cell Longev 2014: 726590, 2014.

This work is licensed under a Creative Commons Attribution-NonCommercial-NoDerivatives 4.0 International (CC BY-NC-ND 4.0) License. 